\title{
Prognosis after surgical replacement with a bioprosthetic aortic valve in patients with severe symptomatic aortic stenosis: systematic review of observational studies
}

\begin{abstract}
Objective To determine the frequency of survival, stroke, atrial fibrillation, structural valve deterioration, and length of hospital stay after surgical replacement of an aortic valve (SAVR) with a bioprosthetic valve in patients with severe symptomatic aortic stenosis.

Design Systematic review and meta-analysis of observational studies. Data sources Medline, Embase, PubMed (non-Medline records only), Cochrane Database of Systematic Reviews, and Cochrane CENTRAL from 2002 to June 2016.

Study selection Eligible observational studies followed patients after SAVR with a bioprosthetic valve for at least two years.

Methods Reviewers, independently and in duplicate, evaluated study eligibility, extracted data, and assessed risk of bias for patient important outcomes. We used the GRADE system to quantify absolute effects and quality of evidence. Published survival curves provided data for survival and freedom from structural valve deterioration, and random effect
\end{abstract}

models provided the framework for estimates of pooled incidence rates of stroke, atrial fibrillation, and length of hospital stay.

Results In patients undergoing SAVR with a bioprosthetic valve, median survival was 16 years in those aged 65 or less, 12 years in those aged 65 to 75 , seven years in those aged 75 to 85 , and six years in those aged more than 85 . The incidence rate of stroke was 0.25 per 100 patient years (95\% confidence interval 0.06 to 0.54 ) and atrial fibrillation 2.90 per 100 patient years (1.78 to 4.79 ). Post-SAVR, freedom from structural valve deterioration was $94.0 \%$ at 10 years, $81.7 \%$ at 15 years, and $52 \%$ at 20 years, and mean length of hospital stay was 12 days ( $95 \%$ confidence interval 9 to 15 ).

Conclusion Patients with severe symptomatic aortic stenosis undergoing SAVR with a bioprosthetic valve can expect only slightly lower survival than those without aortic stenosis, and a low incidence of stroke and, up to 10 years, of structural valve deterioration. The rate of deterioration increases rapidly after 10 years, and particularly after 15 years. 


\section{Introduction}

Aortic valve replacement is the treatment of choice for patients with severe symptomatic aortic stenosis. ${ }^{1}$ Surgical aortic valve replacement (SAVR) reduces morbidity and mortality related to aortic stenosis and has been the procedure of choice for younger, low to intermediate risk patients, typically defined by the Society of Thoracic Surgeons predicted risk of mortality (STS-PROM) score of $8 \%$ or less. ${ }^{1}$ Because such patients require lifelong treatment with oral anticoagulants, ${ }^{2}$ use of mechanical valves has decreased and most SAVR procedures now use bioprosthetic valves.

Options facing patients with severe aortic stenosis include delaying any major procedure, undergoing SAVR with a mechanical valve, undergoing SAVR with a bioprosthetic valve, and undergoing transcatheter aortic valve implantation. Crucial to this decision is mortality after SAVR and structural valve deterioration resulting in heart failure, with possible need for a second valve replacement.

A recent systematic review and meta-analysis of observational studies reporting on long term outcomes with bioprosthetic valves suggest a low incidence for early and late mortality ( $5.03 \%$ per patient year and $1.68 \%$ per patient year, respectively) and a very low rate of reintervention $\left(0.75 \%\right.$ per patient year). ${ }^{3}$ Limitations of this review included failure to age stratify for mortality, the unlikely assumption of a constant hazard for the incidence rate for reintervention, failure to address outcomes of stroke and atrial fibrillation incidence, and failure to formally address the quality of evidence underlying the findings.

We therefore initiated our own systematic review of the prognosis of patients undergoing SAVR with a bioprosthetic valve. We conducted the review in parallel with systematic reviews addressing relative effects of transcatheter aortic valve implantation versus bioprosthetic SAVR in low and intermediate risk patients, ${ }^{4}$ and a related review of patients' values and preferences. ${ }^{5}$ Our review addressed patient important outcomes of survival, stratified by patients' age, and of stroke, atrial fibrillation, length of hospital stay, and structural valve deterioration with SAVR. These outcomes were chosen with the participation of patients who had undergone SAVR.

We conducted these reviews to inform recommendations ${ }^{6}$ for the first in a new series in The BMJ of trustworthy recommendations published in response to potentially practice changing evidence, ${ }^{7}$ so called Rapid Recommendations. For such recommendations, the panel overseeing the new series requires estimates of absolute risk obtained by applying relative risk estimates from randomised trials to best estimates of baseline risk. Such baseline risks ideally come from observational studies that typically enrol more representative patients than do randomised trials, and follow patients for far longer.

\section{Methods}

\section{Data sources and searches}

We created the search strategy informed by a previously published comprehensive systematic search, ${ }^{8}$ with modifications to capture observational studies. We searched Medline, Embase, PubMed (non-Medline records only), Cochrane Database of Systematic Reviews, and Cochrane CENTRAL from conception to 30 June 2016. Supplementary appendix A presents the search strategy. We identified additional references by searching the reference lists of included publications and relevant narrative reviews.

\section{Study selection}

Eligible observational studies enrolled adults ( $\geq 18$ years) with symptomatic aortic stenosis undergoing SAVR using a bioprosthetic valve. We included studies reporting on patients with mechanical valves if results in patients receiving bioprosthetic valves were reported separately or if $80 \%$ or greater of the participants received bioprosthetic valves. Patient important outcomes were identified by the Rapid Recommendations panel responsible for creating recommendations, composed of clinicians, researchers, methodologists, and patients. ${ }^{6}$ Eligible SAVR studies, unrestricted by language, reported on mortality, stroke, atrial fibrillation, structural valve deterioration, index admission length of stay, or postoperative pain. To ensure that our review was relevant to current technologies, we included only studies published after 2006; for the sake of efficiency, we excluded studies enrolling fewer than 50 patients. When more than one study reported on the same population, we used data from all studies that provided relevant comprehensive information.

Seven reviewers, working in pairs, independently screened titles and abstracts of identified citations, evaluating the full text of potentially eligible articles using a standardised screening form (see supplementary appendix B). The Covidence systematic review platform provided software for screening. ${ }^{9}$

\section{Data abstraction and risk of bias assessment}

Ten reviewers, working in pairs and using a standardised form, independently extracted data from eligible studies, including source of data, time frame of recruitment, definition and number of events, and population characteristics, including age, sex, history of coronary artery disease, chronic obstructive pulmonary disease, diabetes, hypertension, atrial fibrillation, and left ventricular ejection fraction, New York Heart Association classification, prior coronary artery bypass grafting, prior myocardial infarction, prior percutaneous coronary intervention, prior stroke or transient ischemic attack, logistic EuroSCORE, STS-PROM score, and concomitant coronary artery bypass grafting. For survival and structural valve deterioration post-SAVR, we applied Digitizeit ${ }^{10}$ to published Kaplan-Meier curves to obtain patient level freedom-from-event estimates over time. For stroke, atrial fibrillation, and structural valve deterioration in studies not presenting Kaplan-Meier curves, we collected the total number of events along with median follow-up time and incidence rates per 100 patient years, and captured information on postoperative length of hospital stay. Data from the Social Security Administration of United States of America ${ }^{11}$ provided life expectancy for the general population for comparison with estimates of survival post-SAVR obtained in our review.

The quality in prognostic studies (QUIPS) ${ }^{12}$ instrument provided criteria for assessing risk of bias in individual studies, including patient selection, study attrition, measurement of prognostic factors, outcome measurement, study confounding, and statistical analysis and reporting (see supplementary appendix C). The instrument rates studies as high, moderate, or low risk of bias. We classified studies with five or six low risk domains as at overall low risk of bias, studies with two or more high risk domains as at overall high risk of bias, and remaining studies as at overall moderate risk of bias.

The grading of recommendations, assessment, development, and evaluation (GRADE) system provided the structure for assessing confidence in prognostic risk estimates ${ }^{13}$ as high, moderate, low, or very low based on considerations of risk of 
bias, consistency, precision, directness, and publication bias. The last was assessed using visual inspection of funnel plots.

\section{Data synthesis and statistical analysis}

Using an established algorithm, we estimated and pooled individual patient data to obtain an overall estimate of survival and freedom from structural valve deterioration. ${ }^{14}$ Owing to the lack of Kaplan-Meier curves for stroke and atrial fibrillation, we combined and presented the study results as incidence rates per 100 patient years post-intervention for each outcome using Metaprop's DerSimonian and Laird random effects model, with a binomial distribution to model within study variability or stabilise variances by applying Freeman-Tukey double arcsine transformation. ${ }^{15}$

We addressed statistical heterogeneity through consistency of point estimates and extent of overlap of confidence intervals. Heterogeneity was not assessed with $\mathrm{I}^{2}$ statistics, as this is typically not useful in prognostic studies with a large sample size and resulting precise estimates. ${ }^{13}$ To identify potential sources of heterogeneity, we performed subgroup analyses for age, valve type, and risk of bias, specified a priori. We hypothesised higher adverse event rates in older patients, in studies that included only bioprosthetic valves versus studies that also included mechanical valves. We established age thresholds consistent with the requirements for Rapid Recommendations: study mean or median age of $\leq 65,65$ to $<75,75$ to $<85$, and $\geq 85 .{ }^{6}$ For survival estimates, we used the log-rank test to compare survival across the different age groups. We defined a half weighted threshold age in which close to $50 \%$ of the total sample, within each age subgroup, is above and below this threshold. For these age thresholds, we obtained life expectancy estimates from the Social Security Administration of United States of America. ${ }^{11}$ We compared our median survival estimates with life expectancy estimates of the US general population.

A two sided P value of 0.05 or less was considered statistically significant. Review Manager 5 and STATA ${ }^{16}{ }^{17}$ provided software for statistical analyses, as well as forest plots and funnel plots.

\section{Patient involvement}

The parallel Rapid Recommendations guideline panel, which included two patients, requested this meta-analysis and included two people with experience of severe aortic stenosis. The patient panel members helped choose the outcomes examined in this systematic review and uniquely highlighted pain and physical function. We were unable to find direct evidence for either of those outcomes. Feedback from the community panel members guided the interpretation and dissemination of our results.

\section{Results}

\section{Study selection and characteristics}

The 93 eligible studies enrolled patients from 1977 to 2013 and reported on 53884 predominantly male patients with aortic stenosis (mean age 53 to 92 years) undergoing aortic valve replacement. Figure $1 \Downarrow$ presents the flow diagram for study selection following the preferred reporting items for systematic reviews and meta-analyses (PRISMA) format. Supplementary appendix $\mathrm{C}$ summarizes the characteristics of the eligible studies.

\section{Risk of bias in individual studies}

Supplementary appendix D summarizes the quality assessment of individual studies. Of the 93 studies, 51 proved at overall low risk of bias. ${ }^{18-68}$ Twenty one of the remaining 42 proved at overall moderate risk of bias ${ }^{69-89}$ and 21 at overall high risk of bias. $^{90-110}$

\section{Survival post-SAVR}

All 85 studies that reported survival post-SAVR analyzed data using a Kaplan-Meier method. Studies provided pooled survival estimates of $89.7 \%$ at two years, $78.4 \%$ at five years, $57.0 \%$ at 10 years, $39.7 \%$ at 15 years, and $24.7 \%$ at 20 years.

Supplementary appendix $\mathrm{H}$ provides the life table that informed estimates for Rapid Recommendations. ${ }^{6}$ A subgroup analysis comparing studies with a mean or median age of $\leq 65,65$ to 75 , 75 to 85 , and more than 85 showed survival at five years of $83.7 \%, 81.4 \%, 67.4 \%$, and $52.2 \%$, respectively (interaction $\mathrm{P}<0.001$, fig $2 \Downarrow$ ). Studies provided approximate median survival estimates of 16 years in patients aged 65 or less (half weighted group age 59, US general population life expectancy 22.2), 12 years in those aged 65 to 75 (half weighted group age 68, US general population life expectancy 15.6), seven years in those aged 75 to 85 (median age 79, half weighted US general population life expectancy 8.7 ), and six years in those aged more than 85 (mean age 92, US general population life expectancy 3.5). ${ }^{11}$ Studies provided similar estimates of survival across risk of bias and valve type. The overall confidence in the estimate of mortality is moderate (table $1 \Downarrow$ ), with the main limitation being serious inconsistency in survival estimates across individual studies.

\section{Stroke post-SAVR}

The seven studies reporting stroke post-SAVR ${ }^{23-90}$ provided number of events both within and beyond the postoperative period as well as median follow-up time, allowing for calculation of incidence rate per 100 patients years. Studies provided a pooled estimate for incidence of stroke of 0.25 per 100 patient years $(95 \%$ confidence interval 0.06 to 0.54 , table $1 \Downarrow$ ). Subgroup analysis comparing studies revealed that chance easily explained differences between studies restricted to patients receiving bioprosthetic valves and those including patients receiving mechanical valves (bioprosthetic only, 0.38 per 100 patients years, 0.22 to 0.58 ; mixed population, 0.12 per 100 patients years, 0.00 to 0.49 ; interaction $\mathrm{P}=0.26$ ), and based on age categories $(<75,0.28$ per 100 patients years, 0.08 to $0.57 ;>75$, 0.55 per 100 patient years, 0.15 to 1.15 ; interaction $\mathrm{P}=0.26$ ). The overall confidence in the estimate of stroke is moderate because of imprecision (table $1 \Downarrow$ ).

\section{Atrial fibrillation post-SAVR}

Two studies including a total of 177 patients reported that 21 developed atrial fibrillation post-SAVR. ${ }^{23} 106$ The pooled incidence rate of these studies was 2.90 per 100 patient years (1.78 to 4.79 ) (table $1 \Downarrow$ ). The small number of studies precluded subgroup analysis. The overall confidence in the estimate of atrial fibrillation is low owing to serious risk of bias and imprecision (table $1 \Downarrow$ ).

\section{Structural valve deterioration}

Twelve studies ${ }^{21-90}$ with published Kaplan-Meier curves including 7603 patients reported on structural valve deterioration after SAVR. Supplementary appendix F presents the definition for structural valve deterioration across all 12 studies. Although the definitions are worded slightly differently, they all objectively defined valve dysfunction as severe stenosis or regurgitation through echocardiographic assessment. Studies estimated a cumulative incidence of $6.0 \%$ by 10 years, $19.3 \%$ 
by 15 years, and $48.0 \%$ by 20 years (fig $3 \Downarrow$ ). Risk of bias assessment deemed all but one study to be at low risk of bias. The overall confidence in the estimates of structural valve deterioration post-SAVR is high.

\section{Length of hospital stay}

The pooled mean estimate for length of hospital stay in 11 studies ${ }^{20-31} 3962^{64-103}$ that enrolled 6405 patients undergoing SAVR was 13 days (95\% confidence interval 10 to 16 , table $1 \Downarrow$ ). Subgroup analysis comparing studies at low risk of bias with those at moderate and high risk of bias showed an interaction $P$ value of 0.05 (low risk of bias, 12 days, 95\% confidence interval 9 to 15 ; high risk of bias, 15 days, 14 to 16). Given the $\mathrm{P}$ value on the test for interaction, we considered the low risk of bias studies to be more trustworthy, providing high confidence in the estimate of length of hospital stay (table $1 \Downarrow$ ).

\section{Postoperative pain}

No eligible studies reported on postoperative pain.

\section{Discussion}

In this systematic review and meta-analysis of outcomes after surgical aortic valve replacement (SAVR) we provide prognostic estimates for patient important outcomes needed to determine absolute effects of SAVR for patient important outcomes. The timeliness of the review is underscored by the potentially practice changing evidence emerging from the Partner 2 trial concerning transcatheter aortic valve implantation as an alternative to SAVR in patients at low to intermediate risk of perioperative mortality. ${ }^{111}$ Our findings, together with linked systematic reviews on treatment effects and patient preferences and values, inform trustworthy recommendations for clinical practice developed in the new The BMJ series Rapid Recommendations. ${ }^{6}$

\section{Principal findings}

From the time of surgery, the approximate median survival in patients undergoing SAVR is 16 years in those aged 65 or less years, 12 years in patients aged 65 to 75 , seven years in those aged 75 to 85 , and six years in those older than 85 (fig $2 \Downarrow$ ). The median survival in patients aged 65 or less years is approximately five years less than that of the general population, but it is similar to the general population in patients older than 65 . Evidence in patients with an average age of more than 85 , taken from a single study, suggested a longer life span than that of the general population of the same age. This likely reflects that only exceptionally healthy patients of this advanced age were considered for SAVR.

Over the decade after SAVR, patients participating in these studies experienced a risk of stroke less than $3 \%$, a risk of atrial fibrillation less than $30 \%$, and a risk of structural valve deterioration less than $10 \%$. The rate of structural valve deterioration, however, increases rapidly after 10 years, with deterioration occurring in almost $50 \%$ of patients by 20 years.

Age has a strong association with mortality; estimates differed according to risk of bias only for duration of hospital stay (lower risk of bias studies reported shorter hospital stay). With respect to stroke, age did not influence the frequency. We found only one study reporting on stroke in patients of mean age 65 or less, and no studies of mean age 85 or more. Thus there is need for future research to better understand the extent to which risk of stroke varies across age groups.
In these studies, patients undergoing SAVR stayed in hospital an average of 12 days (95\% confidence interval 9 to 15 days). We found one study to be an outlier, with a mean length of stay post-SAVR of five days. ${ }^{39}$ Most patients in this study were in New York Heart Association class I and II (89\%). The relatively normal functional status of these patients may be responsible for the shorter length of stay post-surgery. One study, from the German registry on SAVR (not included in our systematic review because it was published after we had completed our search), reported an average length of stay of 12 days, in keeping with our results. ${ }^{112}$

\section{Strengths and limitations of this review}

Strengths of our systematic review include a comprehensive search of databases for all observational studies and a review of citations of not only eligible studies but prior narrative reviews. Reviewers abstracted data and applied the QUIPS instrument for risk of bias, independently and in duplicate. We conducted subgroup analyses exploring the impact of age, risk of bias, and population (all bioprosthetic or mixed) on outcomes. We also rated the confidence in prognostic estimates for each outcome using guidance from the GRADE working group. ${ }^{13}$

One limitation of this review is that the method we used for pooling survival across studies using published Kaplan-Meier curves assumes a constant rate of censoring through time. ${ }^{14}$ The algorithm underlying this method does not consider the standard error in survival estimates and thus the variability in results across studies. This method therefore does not account for the varying sample sizes from which the individual patient data are estimated. Thus we are unable to generate confidence intervals around survival estimates and cumulative incidences. Another limitation of this method is the inability to perform competing risk analysis, which would require individual patient data from source studies. The current analysis captures mortality as a censored event when the outcome of interest is structural valve deterioration. As a result, this modifies the probability of structural valve deterioration, resulting in inaccurate cumulative incidence for this event.

In our survival analysis, we subclassified studies based on prespecified age categories. We classified studies using the reported mean or median age. It is possible for some studies to be classified in one category but have patients that belong to another age category (based on the distribution of age). This likely underestimates differences in survival according to age. Furthermore, only one study had participants with a mean age of 92 , and thus the age group 85 or older is informed by very few patients $(n=119)$.

Our calculation of incidence rate depended on mean or median follow-up and assumed a constant incidence over time. When this is not the case (as it clearly is not for atrial fibrillation and structural valve deterioration) the incidence rates may be misleading.

For instance, two studies reported the absolute number of patients with new onset atrial fibrillation during the follow-up period. Collectively, they provided an incidence rate of 2.90 per 100 patient years. Based on this incidence rate, the risk of new onset atrial fibrillation by four years is $12 \%$. In the PARTNER 2A trial, approximately 27 of 100 patients developed atrial fibrillation by two years. ${ }^{111}$ Our incidence rate is based on a longer median follow-up (four years, versus two years maximum follow-up in PARTNER 2A). The hazard for atrial fibrillation is highest in the postoperative period and much lower thereafter; this to some extent explains the difference in estimates. Other explanations include differences between the 
demographics of patients included in our review and those included in the PARTNER 2A trial. For instance, the average age of patients undergoing SAVR in the PARTNER 2A trial is 81.7 years; the two cohorts that inform our atrial fibrillation incidence rate enrolled patients of mean age 58 and 77 years.

We presented our estimate for length of hospital stay post-SAVR using the mean. The length of stay might be expected to have an upward skewed distribution, necessitating the use of median for reporting the central tendency. Therefore, our reported mean length of stay may be an overestimation as a result of improper statistical reporting of source studies.

We found high quality evidence for length of hospital stay and structural valve deterioration. Imprecision was a common limitation in other outcomes, which also limits subgroup analyses (for instance, we found no association between age and risk of stroke, likely because the analysis was underpowered).

\section{Comparison with other findings}

Our current paper and the previous systematic review and meta-analysis by Huygens et al both address prognosis after SAVR with bioprosthetic valves over a similar period. ${ }^{3}$ The study by Huygens et al, however, failed to age stratify for mortality; our results, not surprisingly, show large differences in mortality across age groups. The study by Huygens et al focused on reinterventions, ignoring the functional deterioration that accompanies structural valve deterioration in those who do not undergo reintervention. In addressing reintervention, these authors made the unlikely assumption of a constant hazard. We utilized a novel method to obtain estimates for structural valve deterioration at all time points post-SAVR, and demonstrate the low rate of structural valve deterioration in the first decade after operation and the rapid increase thereafter, particularly after 15 years. In addition, our review addressed the additional patient important outcomes of atrial fibrillation, stroke, and length of hospital stay. Finally, we utilized the GRADE approach to evaluate confidence in our estimates for all outcomes, establishing that some evidence (structural valve deterioration, stroke) is high quality (and thus trustworthy), some (mortality, stroke) is moderate quality, and some (atrial fibrillation) only low quality.

\section{Conclusion}

For patients who undergo SAVR using a bioprosthetic valve, evidence with moderate to high confidence suggests a survival close to that of general populations of the same age, a low incidence of stroke, and infrequent structural valve deterioration for the first decade, with increasing incidence thereafter.

We thank Heather Ross, Ana Carolina Alba, and Steve Fan for their contributions and guidance.

Contributors: FF performed the literature search and data analysis. FF, RAS, GHG, and POV interpreted the data analysis. FF wrote the first draft of the manuscript. FF, SB, TD, YC, RK, DS, TA, HM, and TS acquired the data and judged risk of bias in the studies. $\mathrm{KO}, \mathrm{MS}$, and EB extracted patient level survival data from Kaplan-Meier curve. Steve Fan and Ana Carolina Alba provided statistical advice. CMO, RAS, POV, GHG, SB, TA, Heather Ross, and RB critically revised the manuscript. POV, RAS, TA, and GHG conceived the study idea. FF had full access to all of the data in the study, and takes responsibility for the integrity of the data and the accuracy of the data analysis. FF is the guarantor.

Funding: This project received no specific funding.
Competing interests: All authors have completed the ICMJE uniform disclosure form at www.icmje.org/coi_disclosure.pdf and declare: no support from any organization for the submitted work; no financial relationships with any organization that might have an interest in the submitted work in the previous three years; no other relationships or activities that could appear to have influence the submitted work.

Ethical approval: Not required.

Data sharing: Abstracted study level and patient level survival data, as well as STATA code will be made publicly available on publication.

Transparency: The lead author (FF) affirms that the manuscript is an honest, accurate, and transparent account of the study being reported; that no important aspects of the study have been omitted; and that any discrepancies from the study as planned have been explained.

1 Nishimura RA, Otto CM, Bonow RO, et al. ACC/AHA Task Force Members. 2014 AHA/ACC Guideline for the Management of Patients With Valvular Heart Disease: executive summary: a report of the American College of Cardiology/American Heart Association Task Force on Practice Guidelines. Circulation 2014:129:2440-92. doi:10.1161/CIR. 0000000000000029 pmid:24589852.

2 Arsalan $\mathrm{M}$, Walther T. Durability of prostheses for transcatheter aortic valve implantation. Nat Rev Cardiol 2016;13:360-7. doi:10.1038/nrcardio.2016.43 pmid:27053461.

3 Huygens SA, Mokhles MM, Hanif M, et al. Contemporary outcomes after surgical aortic valve replacement with bioprostheses and allografts: a systematic review and meta-analysis. Eur J Cardiothorac Surg 2016;ezw101. doi:10.1093/ejcts/ezw101 pmid: 27026750 .

4 Siemieniuk RA, Agoritsas T, Manja V, et al. Transcatheter versus surgical aortic valve replacement in patients with severe aortic stenosis at low and intermediate risk: systematic review and meta-analysis.BMJ;2016:354:15130.

5 Lytvyn L, Guyatt GH, Manja V, et al. Patient values and preferences on transcatheter or surgical aortic valve replacement therapy for aortic stenosis: a systematic review. BMJ Open 2016;6:e014327.

6 Vandvik PO, Otto CM, Siemieniuk RA, et al. Transcatheter or surgical aortic valve replacement for patients with severe, symptomatic, aortic stenosis at low to intermediate surgical risk: a clinical practice guideline. BMJ 2016:354:i5085.

7 Siemieniuk RA, Macdonald H, Agoritsas T, Guyatt GH, Brandt L, Vandvik PO. Introduction to BMJ Rapid Recommendations. BMJ 2016;354:15191.

8 Cao C, Liou KP, Pathan FK, et al. Transcatheter Aortic Valve Implantation versus Surgical Aortic Valve Replacement: Meta-Analysis of Clinical Outcomes and Cost-Effectiveness. Curr Pharm Des 2016;22:1965-77. doi:10.2174/1381612822666160219120713 pmid: 26891807.

9 Fabián J, Bass K, Fischer V, et al. [Dilated cardiomyopathy and heart transplantation]. Bratis/ Lek Listy 1997;98:243-7.pmid:9296828.

10 Forli L, Bollerslev J, Simonsen S, et al. Disturbed energy metabolism after lung and heart transplantation. Clin Transplant 2011;25:E136-43. doi:10.1111/j.1399-0012.2010.01379. x pmid:21158927.

11 Actuarial Life Table, Social Security Administration, United States of America.www.ssa. gov/oact/STATS/table4c6.html.

12 Hayden JA, van der Windt DA, Cartwright JL, Côté P, Bombardier C. Assessing bias in studies of prognostic factors. Ann Intern Med 2013;158:280-6. doi:10.7326/0003-4819158-4-201302190-00009 pmid:23420236.

13 Iorio A, Spencer FA, Falavigna M, et al. Use of GRADE for assessment of evidence about prognosis: rating confidence in estimates of event rates in broad categories of patients. BMJ 2015;350:h870. doi:10.1136/bmj.h870 pmid:25775931.

14 Guyot P, Ades AE, Ouwens MJ, Welton NJ. Enhanced secondary analysis of survival data: reconstructing the data from published Kaplan-Meier survival curves. BMC Med Res Methodol 2012:12:9. doi:10.1186/1471-2288-12-9 pmid-22297116.

15 Nyaga VN, Arbyn M, Aerts M. Metaprop: a Stata command to perform meta-analysis of binomial data. Arch Public Health 2014;72:39. doi:10.1186/2049-3258-72-39 pmid: 25810908.

16 Review Manager (RevMan). (The Nordic Cochrane Centre, The Cochrane Collaboration, 2014).

17 Habedank D, Hummel M, Hetzer R, Anker S. Reversibility of cardiac cachexia after heart transplantation. J Heart Lung Transplant 2005;24:1757-62. doi:10.1016/.j.healun.2005. 02.003 pmid: 16297777 .

18 Accola KD, Scott ML, Palmer GJ, et al. Surgical management of aortic valve disease in the elderly: A retrospective comparative study of valve choice using propensity score analysis. J Heart Valve Dis 2008;17:355-64, discussion 365.pmid:18751463.

19 Ali A, Patel A, Ali Z, et al. Enhanced left ventricular mass regression after aortic valve replacement in patients with aortic stenosis is associated with improved long-term survival. $J$ Thorac Cardiovasc Surg 2011;142:285-91. doi:10.1016/j.jtcvs.2010.08.084 pmid: 21272899.

20 Ashikhmina EA, Schaff HV, Dearani JA, et al. Aortic valve replacement in the elderly: determinants of late outcome. Circulation 2011:124:1070-8. doi:10.1161/ CIRCULATIONAHA.110.987560 pmid:21824918.

21 Aupart MR, Mirza A, Meurisse YA, Sirinelli AL, Neville PH, Marchand MA. Perimount pericardial bioprosthesis for aortic calcified stenosis: 18-year experience with 1133 patients. $J$ Heart Valve Dis 2006;15:768-75, discussion 775-6.pmid:17152784.

22 Auriemma S, D'Onofrio A, Brunelli M, et al. Long-term results of aortic valve replacement with Edwards Prima Plus stentless bioprosthesis: eleven years' follow up. J Heart Valve Dis 2006;15:691-5.pmid:17044376.

23 Aydin E, Yerlikhan OA, Tuzun B, Ozen Y, Sarikaya S, Kirali MK. How to approach aortic valve disease in the elderly: a 25-year retrospective study. Cardiovasc J Afr 2014;25:244-8. doi:10.5830/CVJA-2014-051 pmid:25629541.

24 Barone-Rochette G, Piérard S, De Meester de Ravenstein C, et al. Prognostic significance of LGE by CMR in aortic stenosis patients undergoing valve replacement. J Am Coll Cardiol 2014;64:144-54. doi:10.1016/j.jacc.2014.02.612 pmid:25011718. 


\section{Linked articles in this BMJ Rapid Recommendations cluster}

- Siemieniuk RA, Agoritsas T, Manja V, et al. Transcatheter versus surgical aortic valve replacement in patients with severe aortic stenosis at low and intermediate risk: systematic review and meta-analysis. BMJ 2016;354:15130.

- Meta-analysis of the relative effects of transcatheter aortic valve insertion (TAVI) versus surgical aortic valve replacement (SAVR)

- - Lytvyn L, Guyatt GH, Manja V, et al. Patient values and preferences on transcatheter or surgical aortic valve replacement therapy for aortic stenosis: a systematic review. BMJ Open 2016;6:e014327.

- Review of patients' views of TAVI versus SAVR

- - Vandvik PO, Otto CM, Siemieniuk RA, et al. Transcatheter or surgical aortic valve replacement for patients with severe, symptomatic, aortic stenosis at low to intermediate surgical risk: a clinical practice guideline. BMJ 2016;354:15085.

- Summary of the results from the Rapid Recommendation process

- Magic App (www.magicapp.org)

- Expanded version of the results with multilayered recommendations, evidence summaries, and decision aids for use on all devices

\section{What is already known on this topic}

Surgical aortic valve replacement (SAVR) using a bioprosthetic valve for severe aortic stenosis is often associated with acceptable perioperative and long term mortality, though best prognostic estimates from pooled data are unavailable Valve deterioration is infrequent in the first years after SAVR, but increases subsequently, although best estimates are unavailable

\section{What this study adds}

Patients undergoing SAVR for severe aortic stenosis can anticipate only slightly lower survival than that of the general population of the same age

Long term outcome post-SAVR is associated with a low incidence of stroke and, over 10 years, of structural valve deterioration, though $48 \%$ experience valve deterioration by 20 years

25 Benhameid O, Jamieson WR, Castella M, et al. CarboMedics Mitroflow pericardial aortic bioprosthesis - performance in patients aged 60 years and older after 15 years. Thorac Cardiovasc Surg 2008:56:195-9. doi:10.1055/s-2008-1038385 pmid:18481236.

26 Bourguignon T, Bouquiaux-Stablo AL, Candolfi P, et al. Very long-term outcomes of the Carpentier-Edwards Perimount valve in aortic position. Ann Thorac Surg 2015;99:831-7. doi:10.1016/j.athoracsur.2014.09.030 pmid:25583467.

27 Bourguignon T, Lhommet P, El Khoury R, et al. Very long-term outcomes of the Carpentier-Edwards Perimount aortic valve in patients aged $50-65$ years. Eur $\mathrm{J}$ Cardiothorac Surg 2016:49:1462-8. doi:10.1093/ejcts/ezv384 pmid:26530269.

28 Rubio Alvarez J, Sierra Quiroga J, Vega Fernandez M, et al. Up to twenty-five-year surviva after aortic valve replacement with size $19 \mathrm{~mm}$ valves. Interact Cardiovasc Thorac Surg 2010;10:32-5. doi:10.1510/icvts.2009.209197 pmid:19770137.

29 Christ T, Grubitzsch H, Claus B, Heinze G, Dushe S, Konertz W. Hemodynamic behavio of stentless aortic valves in long term follow-up. J Cardiothorac Surg 2014;9:197. doi:10. 1186/s13019-014-0197-2 pmid:25527116

30 Concistrè $\mathrm{G}$, Dell'aquila $\mathrm{A}$, Pansini $\mathrm{S}$, et al. Aortic valve replacement with smaller prostheses in elderly patients: does patient prosthetic mismatch affect outcomes? J Card Surg 2013;28:341-7. doi:10.1111/jocs.12136 pmid:23691967.

31 Dalén M, Biancari F, Rubino AS, et al. Ministernotomy versus full sternotomy aortic valve replacement with a sutureless bioprosthesis: a multicenter study. Ann Thorac Surg 2015;99:524-30. doi:10.1016/j.athoracsur.2014.08.028 pmid:25483001.

32 de Vincentiis $C$, Kunkl AB, Trimarchi S, et al. Aortic valve replacement in octogenarians: is biologic valve the unique solution?Ann Thorac Surg 2008;85:1296-301. doi:10.1016/j. athoracsur.2007.12.018 pmid:18355513.

33 Eichinger WB, Hettich IM, Ruzicka DJ, et al. Twenty-year experience with the St. Jude medical Biocor bioprosthesis in the aortic position. Ann Thorac Surg 2008;86:1204-10. doi:10.1016/j.athoracsur.2008.05.058 pmid:18805161.

34 EIBardissi AW, Shekar P, Couper GS, Cohn LH. Minimally invasive aortic valve replacement in octogenarian, high-risk, transcatheter aortic valve implantation candidates. $J$ Thorac Cardiovasc Surg 2011;141:328-35. doi:10.1016/j.jtcvs.2010.08.056 pmid: 21047646

35 Elhmidi Y, Piazza N, Mazzitelli D, Wottke M, Lange R, Bleiziffer S. Sex-related differences in 2197 patients undergoing isolated surgical aortic valve replacement. J Card Surg 2014:29:772-8. doi:10.1111/jocs.12442 pmid:25264220.

36 Filsoufi F, Rahmanian PB, Castillo JG, Chikwe J, Silvay G, Adams DH. Excellent early and late outcomes of aortic valve replacement in people aged 80 and older. J Am Geriatr Soc 2008;56:255-61. doi:10.1111/j.1532-5415.2007.01535.x pmid:18047491.

37 Flameng W, Herregods MC, Vercalsteren M, Herijgers P, Bogaerts K, Meuris B. Prosthesis-patient mismatch predicts structural valve degeneration in bioprosthetic heart valves. Circulation 2010;121:2123-9. doi:10.1161/CIRCULATIONAHA.109.901272 pmid: 20439787.

38 Fuchs C, Mascherbauer J, Rosenhek R, et al. Gender differences in clinical presentation and surgical outcome of aortic stenosis. Heart 2010;96:539-45. doi:10.1136/hrt.2009. 186650 pmid:20350991.

39 Gaudino M, Anselmi A, Glieca F, et al. Contemporary results for isolated aortic valve surgery. Thorac Cardiovasc Surg 2011;59:229-32. doi:10.1055/s-0030-1250640 pmid: 21409748.

40 Glauber M, Gilmanov D, Farneti PA, et al. Right anterior minithoracotomy for aortic valve replacement: 10-year experience of a single center. J Thorac Cardiovasc Surg 2015;150:548-56.e2. doi:10.1016/j.jtcvs.2015.06.045 pmid:26215359

41 Grupper A, Beigel R, Maor E, et al. Survival after intervention in patients with low gradien severe aortic stenosis and preserved left ventricular function. $J$ Thorac Cardiovasc Surg 2014;148:2823-7. doi:10.1016/j.jtcvs.2014.03.039 pmid:24787695.

42 Gurvitch R, Wood DA, Tay EL, et al. Transcatheter aortic valve implantation: durability of clinical and hemodynamic outcomes beyond 3 years in a large patient cohort. Circulation 2010;122:1319-27. doi:10.1161/CIRCULATIONAHA.110.948877 pmid:20837893.

43 Gerckens U, et al. Four-year durability and patient survival with CoreValve transcatheter aortic valve. Eur Heart J 2011:32:169. doi:10.1093/eurheartj/ehr322. pmid.20978016.
44 Hong S, Yi G, Youn YN, Lee S, Yoo KJ, Chang BC. Effect of the prosthesis-patient mismatch on long-term clinical outcomes after isolated aortic valve replacement for aortic stenosis: a prospective observational study. J Thorac Cardiovasc Surg 2013:146:1098-104. doi:10.1016/j.jtcvs.2012.07.101 pmid:22959323.

45 Howell NJ, Keogh BE, Ray D, et al. Patient-prosthesis mismatch in patients with aortic stenosis undergoing isolated aortic valve replacement does not affect survival. Ann Thorac Surg 2010;89:60-4. doi:10.1016/j.athoracsur.2009.07.037 pmid:20103206.

46 Iturra SA, Suri RM, Greason KL, et al. Outcomes of surgical aortic valve replacement in moderate risk patients: implications for determination of equipoise in the transcatheter era. J Thorac Cardiovasc Surg 2014;147:127-32. doi:10.1016/j.jtcvs.2013.08.036 pmid: 24094915.

47 Kapadia SR, Tuzcu EM, Makkar RR, et al. Long-term outcomes of inoperable patients with aortic stenosis randomly assigned to transcatheter aortic valve replacement or standard therapy. Circulation 2014;130:1483-92. doi:10.1161/CIRCULATIONAHA.114. 009834 pmid:25205802

48 Kato $Y$, Tsutsumi $Y$, Kawai $T$, Goto $T$, Takahashi $Y$, Ohashi $H$. Aortic valve replacement for aortic stenosis in the elderly: influence of prosthesis-patient mismatch on late survival and left ventricular mass regression. Gen Thorac Cardiovasc Surg 2008;56:397-403. doi: 10.1007/s11748-008-0261-8 pmid:18696205

49 Kobayashi KJ, Williams JA, Nwakanma L, Gott VL, Baumgartner WA, Conte JV. Aortic valve replacement and concomitant coronary artery bypass: assessing the impact of multiple grafts. Ann Thorac Surg 2007:83:969-78. doi:10.1016/j.athoracsur.2006.10. 027 pmid: 17307443.

50 Kulik A, Burwash IG, Kapila V, Mesana TG, Ruel M. Long-term outcomes after valve replacement for low-gradient aortic stenosis: impact of prosthesis-patient mismatch. Circulation 2006;114(Suppl):I553-8.pmid:16820636.

51 Levy F, Laurent M, Monin JL, et al. Aortic valve replacement for low-flow/low-gradient aortic stenosis operative risk stratification and long-term outcome: a European multicenter study. J Am Coll Cardiol 2008:51:1466-72. doi:10.1016/jjacc.2007.10.067 pmid:18402902.

52 Linneweber J, Heinbokel T, Christ T, Claus B, Kossagk C, Konertz W. Clinical experience with the ATS 3F stentless aortic bioprosthesis: five years' follow up. $J$ Heart Valve Dis 2010;19:772-7.pmid:21214103.

53 Matsumoto Y, Fujita T, Hata H, Shimahara Y, Sato S, Kobayashi J. Hemodynamic Performance and Durability of Mosaic Bioprostheses for Aortic Valve Replacement, up to 13 Years. Circ J 2015:79:1044-51. doi:10.1253/circj.CJ-14-0990 pmid:25740500.

54 McLean RC, Briggs AH, Slack R, et al. Perioperative and long-term outcomes following aortic valve replacement: a population cohort study of 4124 consecutive patients. Eur $J$ Cardiothorac Surg 2011;40:1508-14. doi:10.1016/j.ejcts.2011.01.088. pmid:21493086.

55 Muneretto C, Alfieri O, Cesana BM, et al. A comparison of conventional surgery, transcatheter aortic valve replacement, and sutureless valves in "real-world" patients with aortic stenosis and intermediate- to high-risk profile. J Thorac Cardiovasc Surg 2015;150:1570-7, discussion 1577-9. doi:10.1016/j.jtcvs.2015.08.052 pmid:26384753.

56 Muneretto C, Bisleri G, Moggi A, et al. Treating the patients in the 'grey-zone' with aortic valve disease: a comparison among conventional surgery, sutureless valves and transcatheter aortic valve replacement. Interact Cardiovasc Thorac Surg 2015;20:90-5. doi:10.1093/icvts/ivu340 pmid:25320140.

57 Nyawo B, Graham R, Hunter S. Aortic valve replacement with the Sorin Pericarbon Freedom stentless valve: five-year follow up. $J$ Heart Valve Dis 2007;16:42-8.pmid: 17315382.

58 Okamura $\mathrm{H}$, Yamaguchi A, Nagano $\mathrm{H}$, et al. Mid-term outcomes after aortic valve replacement with the 17-mm St. Jude Medical Regent valve. Circ J 2012;76:365-71. doi: 10.1253/circj.CJ-11-0733 pmid:22130314.

59 Oliveira SM, Correia AS, Paiva M, et al Long-term survival, autonomy, and quality of life of elderly patients undergoing aortic valve replacement. J Card Surg 2012;27:20-3. doi: 10.1111/j.1540-8191.2011.01360.x pmid:22211277.

60 Papadopoulos N, Schiller N, Fichtlscherer S, et al. Propensity matched analysis of longterm outcomes following transcatheter based aortic valve implantation versus classic aortic 
valve replacement in patients with previous cardiac surgery. J Cardiothorac Surg 2014:9:99. doi:10.1186/1749-8090-9-99 pmid:24915763.

61 Petrov G, Dworatzek E, Schulze TM, et al. Maladaptive remodeling is associated with impaired survival in women but not in men after aortic valve replacement. JACC CardiovasC Imaging 2014;7:1073-80. doi:10.1016/j.jcmg.2014.06.017 pmid:25306541.

62 Redlich K, Khaladj N, Peterss S, et al. Conventional aortic valve replacement in patients with concomitant coronary artery disease and previous coronary artery bypass grafting in the era of interventional approaches. Eur J Cardiothorac Surg 2011:40:455-62. doi:10. 1016/j.ejcts.2010.11.067. pmid:21256760.

63 Schymik G, Heimeshoff M, Bramlage P, et al. A comparison of transcatheter aortic valve implantation and surgical aortic valve replacement in 1,141 patients with severe symptomatic aortic stenosis and less than high risk. Catheter Cardiovasc Interv 2015;86:738-44. doi:10.1002/ccd.25866 pmid:25641398.

64 Wenaweser P, Pilgrim T, Kadner A, et al. Clinical outcomes of patients with severe aortic stenosis at increased surgical risk according to treatment modality. J Am Coll Cardiol 2011;58:2151-62. doi:10.1016/j.jacc.2011.05.063 pmid:22078420.

65 Yamane K, Hirose H, Youdelman BA, Bogar LJ, Diehl JT. Conventional aortic valve replacement for elderly patients in the current era. Circ J 2011;75:2692-8. doi:10.1253/ circj.CJ-11-0541 pmid:21857141

66 Christ T, Grubitzsch H, Claus B, Konertz W. Long-term follow-up after aortic valve replacement with Edwards Prima Plus stentless bioprostheses in patients younger than 60 years of age. J Thorac Cardiovasc Surg 2014;147:264-9. doi:10.1016/j.jtcvs.2012.10. 032 pmid:23158257.

67 Christ T, Grubitzsch H, Claus B, Konertz W. Stentless aortic valve replacement in the young patient: long-term results. J Cardiothorac Surg 2013;8:68. doi:10.1186/1749-80908-68 pmid:23566631.

68 Joshi V, Prosser K, Richens D. Early prosthetic valve degeneration with Mitroflow aortic valves: determination of incidence and risk factors. Interact Cardiovasc Thorac Surg 2014;19:36-40. doi:10.1093/icvts/ivu033 pmid:24667584.

69 Anselmi A, Flécher E, Ruggieri VG, et al. Long-term results of the Medtronic Mosaic porcine bioprosthesis in the aortic position. J Thorac Cardiovasc Surg 2014;147:1884-91. doi:10.1016/j.jtcvs.2013.07.005 pmid:23988288

70 Beholz S, Repossini A, Livi U, et al. The Freedom SOLO valve for aortic valve replacement: clinical and hemodynamic results from a prospective multicenter trial. $J$ Heart Valve Dis 2010;19:115-23.pmid:20329497.

71 Dagenais F, Mathieu P, Doyle D, Dumont É, Voisine P. Moderate aortic stenosis in coronary artery bypass grafting patients more than 70 years of age: to replace or not to replace? Ann Thorac Surg 2010;90:1495-9, discussion 1499-500. doi:10.1016/j.athoracsur. 2010.06.036 pmid:20971247.

72 Ding WH, Lam YY, Pepper JR, et al. Early and long-term survival after aortic valve replacement in septuagenarians and octogenarians with severe aortic stenosis. Int $J$ Cardiol 2010;141:24-31. doi:10.1016/j.jicard.2008.11.126 pmid:19138807.

73 Dubois C, Coosemans M, Rega F, et al. Prospective evaluation of clinical outcomes in all-comer high-risk patients with aortic valve stenosis undergoing medical treatment, transcatheter or surgical aortic valve implantation following heart team assessment. Interact Cardiovasc Thorac Surg 2013;17:492-500. doi:10.1093/icvts/ivt228 pmid: 23702465.

74 Ennker JA, Ennker IC, Albert AA, Rosendahl UP, Bauer S, Florath I. The Freestyle stentless bioprosthesis in more than 1000 patients: a single-center experience over 10 years. J Card Surg 2009;24:41-8. doi:10.1111/j.1540-8191.2008.00732.x pmid:19120674.

75 George I, Yerebakan H, Kalesan B, et al. Age alone should not preclude surgery: contemporary outcomes after aortic valve replacement in nonagenarians. J Thorac Cardiovasc Surg 2014;148:1360-1369.e1. doi:10.1016/j.jtcvs.2014.01.015 pmid:24560419.

76 Glaser N, Franco-Cereceda A, Sartipy U. Late haemodynamic performance and survival after aortic valve replacement with the Mosaic bioprosthesis. Interact Cardiovasc Thorac Surg 2014;19:756-62. doi:10.1093/icvts/ivu238 pmid:25016530.

77 Gunter RL, Kilgo P, Guyton RA, et al. Impact of preoperative chronic lung disease on survival after surgical aortic valve replacement. Ann Thorac Surg 2013;96:1322-8. do: 10.1016/j.athoracsur.2013.05.061 pmid:23968758

78 Higgins J, Jamieson WR, Benhameid O, et al. Influence of patient gender on mortality after aortic valve replacement for aortic stenosis. J Thorac Cardiovasc Surg 2011;142:595-601, 601.e1-2. doi:10.1016/j.jtcvs.2010.05.056. pmid:21247593.

79 Horst M, Easo J, Hölzl PP, et al. The Freedom SOLO valve: mid-term clinical results with a stentless pericardial valve for aortic valve replacement. $J$ Heart Valve Dis 2011;20:704-10.pmid:22655502.

80 Luciani GB, Viscardi F, Cresce GD, Faggian G, Mazzucco A. Seven-year performance of the Edwards Prima Plus stentless valve with the intact non-coronary sinus technique. J Card Surg 2008:23:221-6. doi:10.1111/j.1540-8191.2008.00592.x pmid:18435636.

81 Milano $A D$, Dodonov $M$, Celiento $M$, et al. The Sorin freedom stentless pericardial valve: clinical and echocardiographic performance at 10 years. Int J Artif Organs 2012;35:481-8. doi:10.5301/ijao.5000103 pmid:22661113.

82 Nguyen TC, Babaliaros VC, Razavi SA, et al. Transcatheter aortic valve replacement has improved short-term but similar midterm outcomes in isolated aortic valve replacement after prior coronary artery bypass grafting. Ann Thorac Surg 2014;98:1316-24. doi:10. 1016/i.athoracsur.2014.05.081 pmid:25149053.

83 Rodés-Cabau J, Pibarot P, Suri RM, et al. Impact of aortic annulus size on valve hemodynamics and clinical outcomes after transcatheter and surgical aortic valve replacement: insights from the PARTNER Trial. Circ Cardiovasc Interv 2014;7:701-11. doi:10.1161/CIRCINTERVENTIONS.114.001681 pmid:25270901.

84 Scherner M, Madershahian N, Kuhr K, et al. Aortic valve replacement after previous heart surgery in high-risk patients: transapical aortic valve implantation versus conventional aortic valve replacement-a risk-adjusted and propensity score-based analysis. $J$ Thorac Cardiovasc Surg 2014;148:90-7. doi:10.1016/j.jtcvs.2013.07.046 pmid:24125091.

85 Sénage T, Le Tourneau T, Foucher Y, et al. Early structural valve deterioration of Mitroflow aortic bioprosthesis: mode, incidence, and impact on outcome in a large cohort of patients. Circulation 2014;130:2012-20. doi:10.1161/CIRCULATIONAHA.114.010400 pmid: 25355912.

86 Stassano P, Di Tommaso L, Vitale DF, et al. Aortic valve replacement and coronary artery surgery: determinants affecting early and long-term results. Thorac Cardiovasc Surg 2006;54:521-7. doi:10.1055/s-2006-924467 pmid:17151966.

87 Une D, Mesana L, Chan V, et al. Clinical Impact of Changes in Left Ventricular Function After Aortic Valve Replacement: Analysis From 3112 Patients. Circulation 2015;132:741-7. doi:10.1161/CIRCULATIONAHA.115.015371 pmid:26304665.
88 Wang TKM, Sathananthan J, Chieng N, Gamble GD, Haydock DA, Ruygrok PN. Aortic valve replacement in over 70- and over 80-year olds: 5 -year cohort study. Asian Cardiovasc Thorac Ann 2014;22:526-33. doi:10.1177/0218492313497950 pmid:24867025.

89 Zannis K, Joffre J, Czitrom D, et al. Aortic valve replacement with the perceval S bioprosthesis: single-center experience in 143 patients. J Heart Valve Dis 2014;23:795-802.pmid:25790630.

90 Amabile $\mathrm{N}$, et al. Long-term results of freestyle stentless bioprosthesis in the aortic position: A single center cohort of 500 patients. Eur Heart J 2014;35:686. doi:10.1093/eurhearti/ ehu324. pmid:24474738.

91 Bernet FH, Baykut D, Grize L, Zerkowski HR. Single-center outcome analysis of 1,16 patients with St. Jude medical and ATS open pivot mechanical heart valves. $J$ Heart Valve Dis 2007;16:151-8.pmid:17484464.

92 D'Onofrio A, Salizzoni S, Agrifoglio M, et al. Medium term outcomes of transapical aortic valve implantation: results from the Italian Registry of Trans-Apical Aortic Valve Implantation. Ann Thorac Surg 2013;96:830-5, discussion 836. doi:10.1016/j.athoracsur. 2013.04.094 pmid:23870695.

93 Dewey TM, Brown D, Ryan WH, Herbert MA, Prince SL, Mack MJ. Reliability of risk algorithms in predicting early and late operative outcomes in high-risk patients undergoing aortic valve replacement. J Thorac Cardiovasc Surg 2008;135:180-7. doi:10.1016/j.jtcvs. 2007.09.011 pmid:18179938.

94 Englberger L, Carrel TP, Doss M, et al. Clinical performance of a sutureless aortic bioprosthesis: five-year results of the 3 Enable long-term follow-up study. $J$ Thorac Cardiovasc Surg 2014;148:1681-7. doi:10.1016/j.jtcvs.2014.03.054 pmid:24787699.

95 Grossi EA, Schwartz CF, Yu PJ, et al. High-risk aortic valve replacement: are the outcomes as bad as predicted?Ann Thorac Surg 2008;85:102-6, discussion 107. doi:10.1016/j. athoracsur.2007.05.010 pmid:18154791.

96 Hartzell M, Malhotra R, Yared K, Rosenfield HR, Walker JD, Wood MJ. Effect of gender on treatment and outcomes in severe aortic stenosis. Am J Cardiol 2011;107:1681-6. doi: 10.1016/j.amjcard.2011.01.059 pmid:21440885.

97 Hosono M, Sasaki $\mathrm{Y}$, Hirai $\mathrm{H}$, et al. Risk factors for late valve-related mortality after aortic valve replacement in elderly patients. Ann Thorac Cardiovasc Surg 2013;19:368-74. doi: 10.5761/atcs.0a.12.01983 pmid:23237930.

98 Kobayashi KJ, Williams JA, Nwakanma LU, et al. EuroSCORE predicts short- and mid-term mortality in combined aortic valve replacement and coronary artery bypass patients. $J$ Card Surg 2009;24:637-43. doi:10.1111/j.1540-8191.2009.00906.x pmid:20078709.

99 Koos R, Reinartz S, Mahnken AH, et al. Impact of aortic valve calcification severity and impaired left ventricular function on 3-year results of patients undergoing transcatheter aortic valve replacement. Eur Radiol 2013;23:3253-61. doi:10.1007/s00330-013-29614 pmid:23821024.

100 Orłowska Baranowska E, Abramczuk E, Grabowski M, et al. Factors affecting long-term survival after aortic valve replacement. Kardiol Pol 2012;70:1120-9.pmid:23180519.

101 Santarpino G, Pfeiffer S, Jessl J, et al. Clinical Outcome and Cost Analysis of Sutureless Versus Transcatheter Aortic Valve Implantation With Propensity Score Matching Analysis. Am J Cardiol 2015;116:1737-43. doi:10.1016/j.amjcard.2015.08.043 pmid:26433277.

102 Sezai A, Osaka S, Yaoita H, et al. Early and Long-Term Outcomes in Japanese Patients Aged 80 Years or Older Undergoing Conventional Aortic Valve Replacement. Ann Thorac Cardiovasc Surg 2015;21:247-53. doi:10.5761/atcs.oa.15-00067 pmid:26004118.

103 Subramanian S, Rastan AJ, Holzhey D, et al. Conventional aortic valve replacement in transcatheter aortic valve implantation candidates: a 5-year experience. Ann Thorac Surg 2012;94:726-9, discussion 729-30. doi:10.1016/.athoracsur.2012.04.068 pmid:22818966.

104 Svennevig JL, Abdelnoor M, Nitter-Hauge S. Twenty-five-year experience with the Medtronic-Hall valve prosthesis in the aortic position: a follow-up cohort study of 816 consecutive patients. Circulation 2007;116:1795-800. doi:10.1161/CIRCULATIONAHA. 106.677773 pmid:17893279.

105 Timek TA, Turfe Z, Hooker RL, et al. Aortic valve replacement in octogenarians with prio cardiac surgery. Ann Thorac Surg 2015;99:518-23. doi:10.1016/j.athoracsur.2014.08. 024 pmid:25195546.

106 Umezu K, Saito S, Yamazaki K, Kawai A, Kurosawa H. Cardiac valvular surgery in dialysis patients: comparison of surgical outcome for mechanical versus bioprosthetic valves. Gen Thorac Cardiovasc Surg 2009;57:197-202. doi:10.1007/s11748-008-0365-1 pmid: 19367452.

107 Vohra HA, Whistance RN, Bolgeri M, et al. Mid-term evaluation of Sorin Soprano bioprostheses in patients with a small aortic annulus $<0 r=20 \mathrm{~mm}$. Interact Cardiovasc Thorac Surg 2010;10:399-402. doi:10.1510/icvts.2009.217844 pmid:19952015.

108 Yakubov SJ, Adams DH, Watson DR, et al. CoreValve United States Clinical Investigators. 2-Year Outcomes After lliofemoral Self-Expanding Transcatheter Aortic Valve Replacement in Patients With Severe Aortic Stenosis Deemed Extreme Risk for Surgery. J Am Coll Cardiol 2015;66:1327-34. doi:10.1016/j.jacc.2015.07.042 pmid:26383718.

109 Yamashita MH, Ye J, Jamieson WR, Cheung A, Lichtenstein SV. Conventional aortic valve replacement remains a safe option in patients aged $>$ or $=70$ years: a 20-year experience. J Heart Valve Dis 2012;21:148-55.pmid:22645847.

110 Yoshikawa K, Fukunaga S, Arinaga K, et al. Long-term results of aortic valve replacement with a small St. Jude medical valve in Japanese patients. Ann Thorac Surg 2008;85:1303-8. doi:10.1016/..athoracsur.2007.12.031 pmid:18355515.

111 Leon MB, Smith CR, Mack MJ, et al. PARTNER 2 Investigators. Transcatheter or Surgical Aortic-Valve Replacement in Intermediate-Risk Patients. N Engl J Med 2016;374:1609-20. doi:10.1056/NEJMoa1514616 pmid:27040324.

112 Holzhey D, Mohr FW, Walther T, et al. Current Results of Surgical Aortic Valve Replacement: Insights From the German Aortic Valve Registry. Ann Thorac Surg 2016;101:658-66. doi:10.1016/j.athoracsur.2015.07.090 pmid:26576751.

\section{Accepted: 19092016}

Published by the BMJ Publishing Group Limited. For permission to use (where not already granted under a licence) please go to http://group.bmj.com/group/rights-licensing/ permissions

This is an Open Access article distributed in accordance with the Creative Commons Attribution Non Commercial (CC BY-NC 3.0) license, which permits others to distribute, remix, adapt, build upon this work non-commercially, and license their derivative works on different terms, provided the original work is properly cited and the use is non-commercial. See: http://creativecommons.org/licenses/by-nc/3.0/. 


\section{Table}

Table 1/ GRADE evidence profile on risk estimates summarizing findings from observational studies of surgical aortic valve replacement in patients with severe aortic stenosis

\begin{tabular}{|c|c|c|c|c|c|c|c|c|c|c|}
\hline \multirow{2}{*}{$\begin{array}{l}\text { No of } \\
\text { studies }\end{array}$} & \multicolumn{6}{|c|}{ Quality assessment } & \multicolumn{3}{|c|}{ Effect } & \multirow[t]{2}{*}{ Quality } \\
\hline & Study design & $\begin{array}{c}\text { Risk of } \\
\text { bias }\end{array}$ & Inconsistency & Indirectness & Imprecision & $\begin{array}{c}\text { Other } \\
\text { considerations }\end{array}$ & $\begin{array}{l}\text { No of } \\
\text { events }\end{array}$ & $\begin{array}{c}\text { No of } \\
\text { individuals }\end{array}$ & $\begin{array}{l}\text { Estimate }(95 \% \\
\mathrm{Cl})\end{array}$ & \\
\hline \multicolumn{11}{|c|}{ Survival (follow-up median 4.7 years; assessed with Kaplan-Meier) } \\
\hline 85 & $\begin{array}{l}\text { Observational } \\
\text { studies }\end{array}$ & $\begin{array}{l}\text { Not } \\
\text { serious }\end{array}$ & Serious* & Not serious & Not serious & None & 14053 & 45347 & $\begin{array}{l}\text { Survival at } 5 \\
\text { years } \leq 65 \\
83.7 \% ; 65-75 \\
81.4 \% ; 75-85 \\
67.4 \% ; \text { and } \\
>85,52.2 \%\end{array}$ & Moderate \\
\hline \multicolumn{11}{|c|}{ Stroke (follow-up median 5.1 years; assessed with incidence rate per 100 patient years) } \\
\hline 8 & $\begin{array}{l}\text { Observational } \\
\text { studies }\end{array}$ & $\begin{array}{l}\text { Not } \\
\text { serious }\end{array}$ & Not serious & Not serious & Serious $†$ & None & 64 & 6702 & $\begin{array}{l}\text { Event rate } 0.26 \\
\text { per } 100 \text { person } \\
\text { years }(0.06 \text { to } \\
0.54)\end{array}$ & Moderate \\
\hline \multicolumn{11}{|c|}{ Atrial fibrillation (follow-up mean 4.1 years; assessed with incidence rate per 100 patient years) } \\
\hline 2 & $\begin{array}{l}\text { Observational } \\
\text { studies }\end{array}$ & Serious & Not serious & Not serious & Serioust & None & 21 & 177 & $\begin{array}{l}\text { Event rate } 2.90 \\
\text { per } 100 \text { person } \\
\text { years }(1.78 \text { to } \\
4.79)\end{array}$ & Low \\
\hline \multicolumn{11}{|c|}{ Structural valve deterioration (follow-up median 6.4 years; assessed with Kaplan-Meier) } \\
\hline 12 & $\begin{array}{l}\text { Observational } \\
\text { studies }\end{array}$ & $\begin{array}{l}\text { Not } \\
\text { serious }\end{array}$ & Not serious & Not serious & Not serious & None & 418 & 7703 & $\begin{array}{l}6.0 \%, 19.3 \%, \\
\text { and } 48 \% \text { by } 10, \\
15, \text { and } 20 \\
\text { years, } \\
\text { respectively }\end{array}$ & High \\
\hline \multicolumn{11}{|c|}{ Length of hospital stay (assessed with mean; scale 0 to 100 ) } \\
\hline 7 & $\begin{array}{l}\text { Observational } \\
\text { studies }\end{array}$ & $\begin{array}{l}\text { Not } \\
\text { serious }\end{array}$ & Not serious & Not serious & Not serious & None & - & 6405 & $\begin{array}{l}\text { Mean } 12 \text { (9 to } \\
15)\end{array}$ & High \\
\hline
\end{tabular}

*Wide variety of individual Kaplan-Meier curves around overall mega Kaplan-meier curve.

†Wide confidence interval around the point estimate of incidence rate. 


\section{Figures}

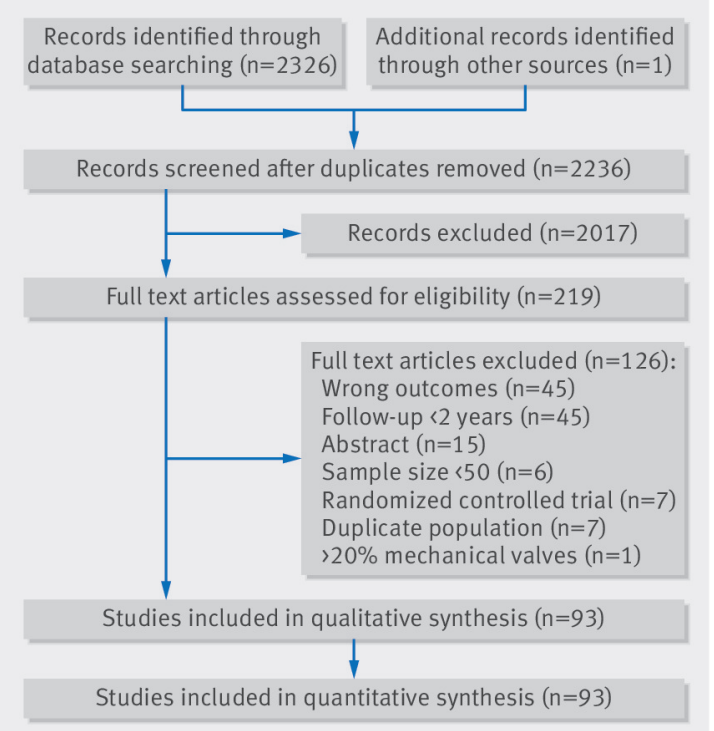

Fig 1 Study flow diagram

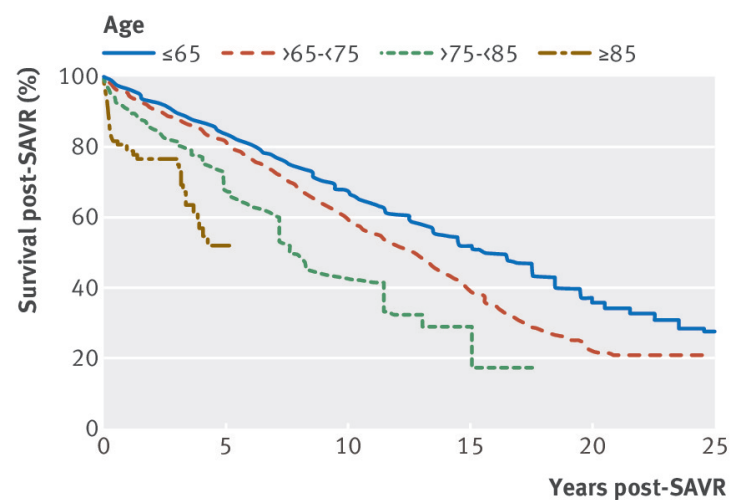

Fig 2 Survival after surgical replacement of an aortic valve with a bioprosthetic valve, stratified by age. Individual patient data estimated using algorithm developed by Guyot et al $2012^{14}$

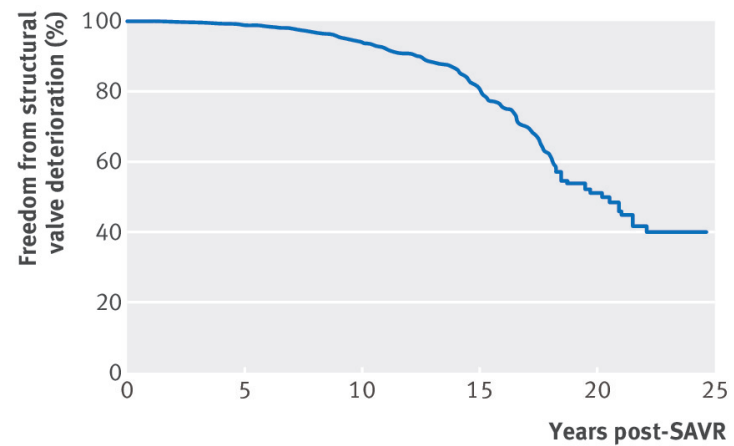

Fig 3 Freedom from structural valve deterioration after surgical aortic valve replacement with a bioprosthetic valve. Individual patient data estimated using algorithm developed by Guyot et al $2012^{14}$ 